Sádhanā, Vol. 18, Part 5, September 1993, pp. 801-813. (C) Printed in India.

\title{
System dynamic performance: Robust stabilization of controls over a range of operating conditions
}

\author{
V VITTAL, M H KHAMMASH and C D PAWLOSKI \\ Department of Electrical Engineering and Computer Engineering, lowa \\ State University, Ames, IA 50011, USA
}

\begin{abstract}
This paper presents a novel approach to analyse stabiiity robustness of controls in power systems over a range of operating conditions. The controls considered include exciters, power system stabilizers, and governors. The analytical basis for the approach is presented. The robustness framework for power systems is formulated. Numerical results for a sample test system are obtained and compared with those obtained by conventional techniques.
\end{abstract}

Keywords. Robustness; control performance; uncertainty/perturbation; system matrix; spectral radius.

\section{Introduction}

In recent years, electric power systems have become more complex. Available transmission and generation is highly utilized, with large amounts of power interchanged among companies and geographical regions. To a large extent adequate system dynamic performance now depends on proper performance of controls such as excitation systems, power system stabilizers (PSS), static var compensators, and special HVDC controls. Proper design and robust performance of these controls is essential for the reliable operation of the interconnected power system.

The North American interconnection has seen an increase in economy transfers as well as security transfers. This has led to several instances (Cressap \& Hauer 1981; Kundur et al 1989a) of low frequency oscillations being observed in practice that involve entire areas of the interconnection. This phenomenon is called the interarea oscillations, and is receiving increased attention by the utility industry. Controls once again are the main tools used for the mitigation of the interarea oscillation. Hence, a careful design and robust performance of controls is imperative for reliable and secure system performance.

To a large extent, the current industry practice for the analysis and design of controls consists of conventional linear analysis coupled with detailed nonlinear simulation of the designed control settings (Martins \& Lima 1990; Roger \& Kundur 1990).

The basic design philosophy consists of linearizing the system around the worst-case loading condition and using conventional linear analysis tools for analysis and design 
of the control settings. In the linearization process the effects of the various nonlinearities are eliminated and only localization of the original nonlinear system around the operating point is considered. The design tools consist mainly of conventional time domain and frequency domain analyses together with modern state space techniques using eigenvalues and eigenvectors.

The designed controls are then tested for robustness over a wide range of operating conditions using detailed time-domain simulation of the nonlinear system. This predicates an accurate model of the system and consideration of a comprehensive range of operating conditions. This procedure is practical and has served the purpose. It, however, lacks a systematic approach and does not guarantee robustness.

The past ten years or so have witnessed an explosion of controls research mainly directed at understanding the robustness properties of control systems. The purpose of these efforts is to obtain closed loop systems which are stable and which meet performance objectives despite the presence of plant uncertainty and parameter variations. Kharitonov (1978) addressed the problem of parameter uncertainty and triggered several efforts directed at extending his results to more general settings.

In the $H^{\infty}$ framework, Doyle (1982) introduced the structural singular value (SSV) approach alternatively referred to as the $\mu$-function. This approach handles multiple perturbations which are norm-bounded linear time-invariant. A similar concept has also been developed by Safanov (1982). Dahleh \& Ohta (1988) give necessary and sufficient conditions for stability robustness in the presence of unstructured nonlinear possibly time-varying perturbations. Recent results (Khammash \& Pearson 1991, 1993; Khammash 1993) provide a complete solution to the robustness analysis problem in the presence of linear time-varying and/or nonlinear structured perturbations. Both the stability robustness problem and the performance robustness problem are considered. The necessary and sufficient conditions obtained for robustness are both simple and computationally feasible, making this approach very attractive especially for problems with a large number of perturbation blocks as is the case in large scale interconnected systems including power systems.

In the approach presented in this paper we use the procedure developed by Khammash (1993). The analytical details of the approach are presented in $\S 2$. We formulate the robustness framework for the power system. Stability robustness of control settings for power system stabilizers, exciters, and governors is then analysed over a range of operating conditions. The formulation has the capability to include any additional control features and is not limited to the control features considered. The formulation is presented in $\S 3$. One of the salient features of the robustness approach presented is the ability to provide systematic and computable necessary and sufficient conditions for stability robustness of large-scale systems. This great reduction in computation is attributed to the simplicity of the derived conditions for robustness which consists of computing the spectral radius of a certain non-negative matrix obtained from the dynamical equations governing the system. In $\S 4$ a sample test system (Klein et al 1991) specifically designed to analyse the effect of controls on the interarea mode is used to test the procedure. The results obtained are compared with those obtained using the conventional eigenvalue techniques.

\section{Analytical background}

The standard setup for a general robustness problem appears in figure 1 . In the figure, $G_{0}$ is a nominal linear time-invariant plant. $G_{0}$ may be continuous-time or discrete- 


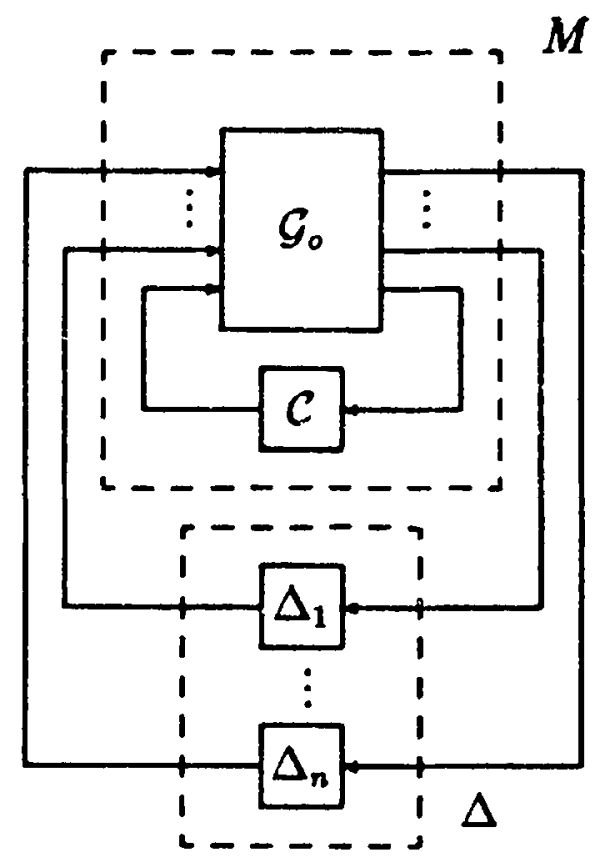

Figure 1. System with structured uncertainty.

time. $C$ is a linear controller stabilizing $G_{0}$. For the analysis problem, $C$ is assumed given and fixed. The uncertainty is modelled with perturbation blocks $\Delta_{1}, \ldots, \Delta_{n}$. Each perturbation $\Delta_{i}$ belongs to the following class of admissible perturbations:

$$
\Delta=\left\{\Delta: \Delta \text { is causal, and }\|\Delta\|:=\sup _{w \neq 0} \frac{\|\Delta u\|_{\infty}}{\|u\|_{\infty}} \leqslant 1\right\} \text {, }
$$

where the norm used is the $L^{\infty}$ norm (or $l^{\infty}$ norm for discrete-time systems). The perturbations may therefore be nonlinear or time-varying. The $n$ perturbation blocks can be lumped into one perturbation block with a diagonal structure. Hence we can view the class of admissible perturbations as the class of all $\Delta \in D(n)$ where

$$
D(n):=\left\{\operatorname{diag}\left(\Delta_{1}, \ldots, \Delta_{n}\right): \Delta_{i} \in \Delta\right\} .
$$

Similarly, $G_{0}$ and $C$ can be lumped into one system $M . M$ is therefore, linear, timeinvariant, casual, and stable. Any weighting on any of the perturbations can be lumped into $M$. It follows that the system in figure 1 can be transformed into that in figure 2 .

Consider the system in figure 2 . The system is said to achieve robust stability if it is $L^{\infty}$-stable for all admissible perturbations, i.e., for all $\Delta \in D(n)$. We next provide necessary and sufficient conditions for robust stability. These conditions will be stated in terms of $M$. From the figure, $M$ has $n$ inputs and $n$ outputs corresponding to the inputs and outputs of the perturbations. Consequently, $M$ can be represented by the

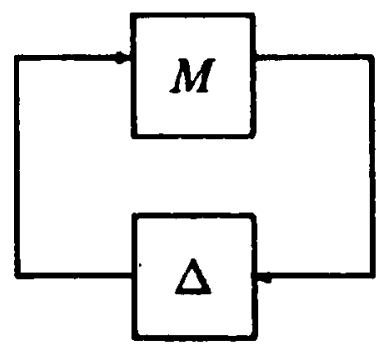

\section{$\Delta \in \mathcal{D}(n)$}

Figure 2. Stability robustness problem. 
system matrix,

$$
M=\left[\begin{array}{lll}
M_{11} & & M_{1 n} \\
\vdots & \cdots & \vdots \\
M_{n 1} & & M_{n n}
\end{array}\right]
$$

In particular, $M_{i j}$ is given by the transfer function between the output of $\Delta_{j}$ and the input to $\Delta_{i}$, will all the perturbations. $\Delta_{1}, \ldots, \Delta_{n}$ set to zero.

Whenever $M$ is finite-dimensional, it admits a state space realization of the form:

where

$$
\begin{aligned}
& \dot{x}=A x+B u, \\
& y=C x+D u,
\end{aligned}
$$

$$
C=\left[\begin{array}{l}
C_{1} \\
\vdots \\
C_{n}
\end{array}\right], \quad B=\left[B_{1} \cdots B_{n}\right], \quad D=\left[\begin{array}{lll}
D_{11} & \cdots & D_{1 n} \\
\vdots & & \vdots \\
D_{n 1} & \cdots & D_{n n}
\end{array}\right] .
$$

$u$ is an $n$ vector input to $M$ which corresponds to the perturbations' output, $y$ is an $n$ vector output corresponding to the perturbations' inputs. Each $M_{i j}$ has induced norm which we refer to as the $A$ norm. It can arbitrarily be computed accurately since

$$
\left\|M_{i j}\right\|_{A}=\left|D_{i j}\right|+\sum_{k=0}^{\infty}\left|C_{i} A^{k} B_{j}\right|
$$

in the discrete time case, and

$$
\left\|M_{i j}\right\|_{A}=\left|D_{i j}\right|+\int_{0}^{\infty}\left|C_{i} e^{A t} B_{j}\right| \mathrm{d} t
$$

in the continuous-time case. We can therefore define the following matrix:

$$
\hat{M}=\left[\begin{array}{lll}
\left\|M_{11}\right\|_{A} & \cdots & \left\|M_{1 n}\right\|_{A} \\
\vdots & & \vdots \\
\left\|M_{n 1}\right\|_{A} & \cdots & \left\|M_{n n}\right\|_{A}
\end{array}\right]
$$

As the next theorem shows, it turns out that $\hat{M}$ plays a fundamental role in the robustness of the given system. We now state the main theorem establishing nonconservative conditions for robustness.

Theorem 1. The system in figure 2 achieves robust stability if and only if any one of the following conditions holds:

(1) $\rho(\hat{M})<1$, where $\rho(\cdot)$ denotes the spectral radius.

(2) $\inf _{R \in R}\left\|R^{-1} M R\right\|_{A}<1$, where $R:=\left\{\operatorname{diag}\left(r_{1}, \ldots, r_{n}\right): r_{i}>0\right\}$.

This theorem, due to Khammash \& Pearson $(1991,1993)$ in the discrete-time case and to Khammash (1993) in the continuous-time case, reduces the robustness analysis problem to that of computing the spectral radius of a non-negative matrix. The theory for non-negative matrices (see e.g. Berman \& Blemmons 1979) provides power algorithms for fast computation of the spectral radius of a non-negative matrix. As a 
result, the robustness condition can be computed exactly and efficiently and thus is especially suited for systems with a large number of uncertainty blocks.

\section{Robustness framework for power systems}

The robustness approach presented in $\S 2$ is now formulated for power systems. The stability robustness of a group of control settings (gains and time constants) for power system stabilizers, exciters, and governors is verified over a range of loading conditions. A nominal loading condition is considered and the system is linearized at the steady state solution.

Perturbations are then considered at each load bus for both the real power and reactive power portions. This introduces perturbations in the diagonal entries of the load bus elements in the network admittance matrix, since the loads are modelled as constant impedances. In addition, perturbations are introduced over the elements of the system, $A, B, C$, and $D$ matrices. The lower and upper bounds on the ranges of these perturbations are determined by running power flows at the extreme load conditions.

We will now describe the development of the $M$ matrix, discussed in $\S 2$, using only the perturbations on the load bus entries of the admittance matrix. A similar approach is followed to include the perturbations on the $A, B, C$, and $D$ matrices.

Perturbations on the diagonal entries of the load buses in the admittance matrix affect the relationship between the injected currents in the network and the terminal voltages. In the linearized equations in the network reference frame, this is governed by

where

$$
\left[\frac{I_{Q, D_{\Delta}}}{Q}\right]=\left[\frac{Y_{m n}}{Y_{m n}} \mid \frac{Y_{m m}}{Y_{m m}}\right]\left[\frac{V_{Q, D_{\Delta}}}{V_{l Q, D_{\Delta}}}\right],
$$

$I_{Q, D_{\Delta}}=$ vector of injected currents at the generator terminal buses,

$V_{Q, D_{\Delta}}=$ vector of generator terminal bus voltages,

$V_{Q, D_{\Delta}}=$ vector of load bus voltages.

Equation (7) can be simplified to obtain

$$
\begin{aligned}
I_{Q, D_{\Delta}} & =\left[Y_{n n}-Y_{n m} Y_{m m}^{-1} Y_{m n}\right] V_{Q, D_{\Delta}} \\
& =\hat{Y}_{n n} V_{Q, D_{\Delta}} .
\end{aligned}
$$

Based on the preliminaries presented in $\S 2$, the $M$ matrix is derived by determining the relationship that exists between the outputs of the perturbations and the inputs to the perturbations taking into account the dynamics of the linearized system with the controllers.

In arriving at the linearized differential equations for the system we consider the following representation for the synchronous machines (SM), exciters (EXC), power system stabilizers (PSS), and governors (GOV). The synchronous machines are represented by the two-axis model (Anderson \& Fouad 1977, chap. 4) given by

$$
\begin{aligned}
& \tau_{d o_{i}}^{\prime} \dot{E}_{q_{i}}^{\prime}=E_{F D_{i}}-E_{q_{i}}^{\prime}+\left(x_{d_{i}}-x_{d_{i}}^{\prime}\right) I_{d_{i}}, \\
& \tau_{q o_{i}}^{\prime} \dot{E}_{d_{i}}^{\prime}=-E_{d_{i}}^{\prime}-\left(x_{q_{i}}-x_{q i}^{\prime}\right) I_{q_{i}},
\end{aligned}
$$




$$
\begin{aligned}
M_{i} \dot{\omega}_{i} & =P_{m_{i}}-D_{i} \omega_{i}-\left[E_{d_{i}}^{\prime} I_{d_{i}}+E_{q i}^{\prime} I_{q i}-\left(x_{q i}^{\prime}-x_{d_{i}}^{\prime}\right) I_{d_{i}} I_{q_{i}}\right] \\
\delta_{i} & =\omega_{i}-1, \quad i=1,2, \ldots, n .
\end{aligned}
$$

A fast static exciter model given in Klein et al (1991) is used. The power system stabilizer is represented by an extended transient midterm stability program (ETMSP) (Kundur et al 1989b) type 1 model, and the governor-turbine by an ETMSP (Kundur et al 1989b) type 8 model.

The linearized system equations are then interfaced with the network equations to obtain the overall state space representation of the system. In interfacing the networking equations to the system dynamic equations appropriate reference frame transformations (Anderson \& Fouad 1977, chap. 9) have to be performed. The process is summarized in figure 3 , where

$$
\begin{aligned}
& T_{0}=\left[\begin{array}{ccccccc}
\cos \delta_{10} & -\sin \delta_{10} & 0 & 0 & \cdots & 0 & 0 \\
\sin \delta_{10} & \cos \delta_{10} & 0 . & 0 & \cdots & 0 & 0 \\
0 & 0 & \cos \delta_{20} & -\sin \delta_{20} & \cdots & \vdots & \\
0 & 0 & \sin \delta_{20} & \cos \delta_{20} & \cdots & \vdots & \vdots \\
\vdots & \vdots & \vdots & \vdots & & \vdots & \vdots \\
\vdots & \vdots & \vdots & \vdots & & \vdots & \vdots \\
0 & 0 & 0 & 0 & \cdots & \cos \delta_{n o} & -\sin \delta_{n o} \\
0 & 0 & 0 & 0 & \cdots & \sin \delta_{n o} & \cos \delta_{n o}
\end{array}\right] \\
& V_{q d o}=\left[\begin{array}{cccc}
-V_{d 10} & 0 & \cdots & 0 \\
V_{q 10} & 0 & \cdots & 0 \\
0 & -V_{d 2 o} & \cdots & 0 \\
0 & V_{q 20} & \cdots & 0 \\
\vdots & \vdots & & \vdots \\
\vdots & \vdots & & \vdots \\
0 & 0 & \cdots & -V_{d n o} \\
0 & 0 & \cdots & V_{q n o}
\end{array}\right], I_{q d o}=\left[\begin{array}{cccc}
-I_{d 1 o} & 0 & \ldots & 0 \\
I_{q 10} & 0 & \ldots & 0 \\
0 & -I_{d 2 o} & \ldots & 0 \\
0 & I_{q 20} & \cdots & 0 \\
\vdots & \vdots & & \vdots \\
\vdots & \vdots & & \vdots \\
0 & 0 & \ldots & -I_{d n o} \\
0 & 0 & \ldots & I_{q n o}
\end{array}\right] \text {, } \\
& Z_{S M_{\Delta}}=\left[\begin{array}{ccccccc}
r_{1} & -x_{d 1}^{\prime} & 0 & 0 & \cdots & 0 & 0 \\
x_{q 1}^{\prime} & r_{1} & 0 & 0 & \cdots & 0 & 0 \\
0 & 0 & -r_{2}^{\prime} & -x_{d 2}^{\prime} & \cdots & 0 & 0 \\
0 & 0 & x_{q 2}^{\prime} & r_{2} & \cdots & 0 & 0 \\
\vdots & \vdots & \vdots & \vdots & & \vdots & \vdots \\
0 & 0 & 0 & 0 & \cdots & r_{n} & -x_{d n}^{\prime} \\
0 & 0 & 0 & 0 & \cdots & x_{q n}^{\prime} & r_{n}
\end{array}\right] .
\end{aligned}
$$

The variables with the subscript o represent the steady state conditions for the variables of the nominal system.

In obtaining figure 3 , the absolute values of the perturbations are normalized to 1. This is done by selecting the nominal value to be the midpoint of the upper and lower ranges. The perturbation is then normalized to 1 and the weighting factor given by the difference between the nominal value and the upper or lower bound is pulled 


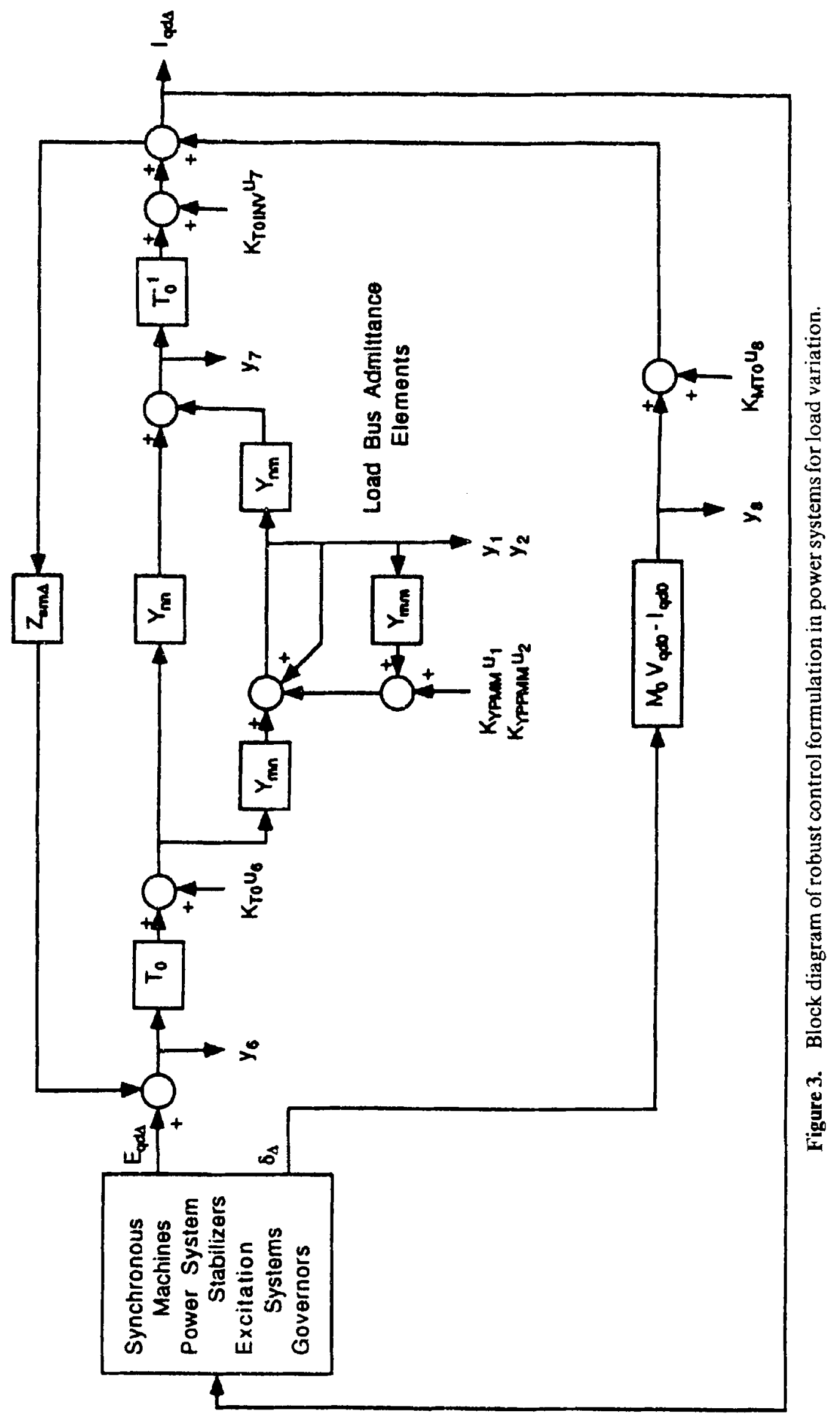


into the system matrix. In addition, the case of perturbations on the load results in complex perturbations associated with admittance entry corresponding to the load buses. The theory presented in $\S 2$ allows only real perturbations. As a result, we separate the real and imaginary parts of $(8)$ as follows:

$$
\begin{aligned}
{\left[I_{Q \Delta}+j I_{D \Delta}\right] } & =\left[\hat{G}_{n n}+j \hat{B}_{n n}\right]\left[V_{Q \Delta}+j V_{D \Delta}\right], \\
{\left[\begin{array}{l}
I_{Q \Delta} \\
I_{D \Delta}
\end{array}\right] } & =\left[\begin{array}{ll}
\hat{G}_{n n}-\hat{B}_{n n} \\
\hat{B}_{n n} & \hat{G}_{n n}
\end{array}\right]\left[\begin{array}{l}
V_{Q \Delta} \\
V_{D \Delta}
\end{array}\right] .
\end{aligned}
$$

From (10) one observes that the input and output relationship of the network results in a repetition of the conductance and admittance elements. If these elements are perturbed, then the perturbations have to be repeated to capture the change in conditions.

The range on the entries corresponding to the load admittance is determined by conducting power flows at the extreme loading conditions. The nominal case is selected at the midpoint of the range. Then

$$
\left|G_{l_{i t}}\right| \leqslant \gamma_{G_{i b}}, \quad\left|B_{l_{i t}}\right| \leqslant \gamma_{B l_{i}}, \quad \text { where } Y_{l_{i t}}=G_{l_{i t}}+j B_{l_{i t}} .
$$

The perturbations are normalized to 1 , and the weighting factor pulled into the system matrix. This is represented in figure 3 by $K_{Y P M M}$ where

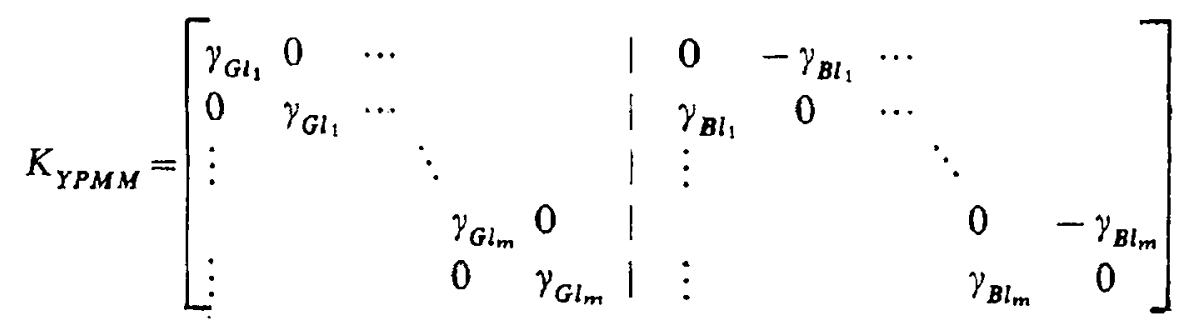

assuming there are $m$ load buses.

Similarly in figure $3, K_{Y P P M M}$ are the gains due to the perturbations on the shunt capacitor elements. $K_{T_{0}}$ and $K_{T O I N V}$ are the gains due to perturbations on $T_{0}$ and $T_{o}^{-1}$, respectively. In addition, due to the change in operating conditions perturbation gains are also obtained on the synchronous machine blocks and the exciter blocks.

The overall system representation is then given by

where

$$
\begin{aligned}
\dot{x} & =A_{\text {sys }} x+B_{1} u_{1}, \\
y_{1} & =C_{1 E q d \Delta} E_{q d \Delta}+C_{1 \delta \Delta} \delta_{\Delta}+D_{11} u_{1},
\end{aligned}
$$

and

$$
\begin{aligned}
D_{1 E q d \Delta} & =\left(Y_{m m}^{-1} Y_{m n} T_{o}\right)\left(U-Z_{S M \Delta} \hat{M}_{o} M_{o}\right), \\
C_{1 \delta \Delta} & =-\left(Y_{m m}^{-1} Y_{m n} T_{o}\right)\left(Z_{S M \Delta} \hat{M}_{o} \hat{M}_{o}\right), \\
D_{11} & =-\left(U+Y_{m m}^{-1} Y_{m n} T_{o} Z_{S M \Delta} \hat{M}_{0} T_{o}^{-1} Y_{n m}\right) Y_{m m}^{-1} K_{Y P M M},
\end{aligned}
$$

$$
\begin{aligned}
U & =\text { identity matrix, } \\
M_{0} & =T_{0}^{-1} \hat{Y}_{x \pi} T_{0}, \\
\hat{M}_{0} & =\left(u+M_{0} Z_{S M \Delta}\right)^{-1}, \\
\tilde{M}_{0} & =M_{0} V_{d g_{0}}-I_{q d_{0}},
\end{aligned}
$$




$$
\begin{aligned}
X & =\left[X_{\mathrm{SM}}, X_{\mathrm{PSS}}, X_{\mathrm{EXC}}, X_{\mathrm{GOV}}\right]^{T}, \\
E_{q d_{o}} & =\left[E_{q 1 \Delta}^{\prime} E_{d 1 \Delta}^{\prime} \cdots E_{q n \Delta}^{\prime} E_{d n \Delta}^{\prime}\right]^{T}, \\
S_{\Delta} & =\left[\delta_{1 \Delta}, \delta_{2 \Delta}, \ldots, \delta_{n \Delta}\right]^{T} .
\end{aligned}
$$

$A_{\text {sys }}$ and $B_{1}$ can be derived knowing the linearized representation of the synchronous machine, exciters, PSS, and governors (Kundur et al 1988).

The representation (Khammash 1993) is then used to obtain the norm matrix shown in (6) using (5b). In the derivation of the norm matrix, it is important to note that with the inclusion of the $n$-machine angles as states, the matrix $A_{\text {sys }}$ for the nominal conditions has a zero eigenvalue which is unobservable but controllable. The minimal realization of the system is obtained before the norm matrix is evaluated. This ensures that the system matrix has all eigenvalues with negative real parts.

\section{Numerical results}

The robustness procedure developed in this paper is tested on a sample system developed in Klein et al (1991). This system exhibits the interarea mode phenomenon, and has the complexity to verify the efficacy of the procedure developed. Figure 4 gives a one-line diagram of the system. We consider two different network topologies:

(a) Two tie-lines in service and area 1 is exporting $400 \mathrm{MW}$ to area 2 . We then analyse the robust performance of the controls for a range of variations of load 1 and load 2 . In our analysis we consider a $200 \mathrm{MW}$ variation in each load; load $11127-1327 \mathrm{MW}$ and load 2 1767-1967 MW.

(b) One tie-line in service and area 1 is exporting $400 \mathrm{MW}$ to area 2. Load 1 is varied over the range $1247-1267 \mathrm{MW}$ and load 2 over $1927-1967 \mathrm{MW}$.

For the range of variations of loads considered we analyse the system for the following configurations.

Case 1: Four fast exciters with four power system stabilizers (PSS).

Case 2: Four fast exciters, with only one PSS, in the area exporting power on GEN2.

Case 3: Four fast exciters, with only one PSS, in the area exporting power on GEN12.

Case 4: Four fast exciters witn no PSS.

The settings for the exciters are given by Klein et al (1991). The PSs settings were as follows: $K_{s}=15, T_{5}=10, T_{1}=0.047, T_{2}=0.021, T_{3}=3.0, T_{4}=5.4$. For each case the $M$ matrix was calculated including perturbations in the loads and the system $A$, $B, C$, and $D$ matrices. In evaluating the $M$ matrix, the integration of the exponential

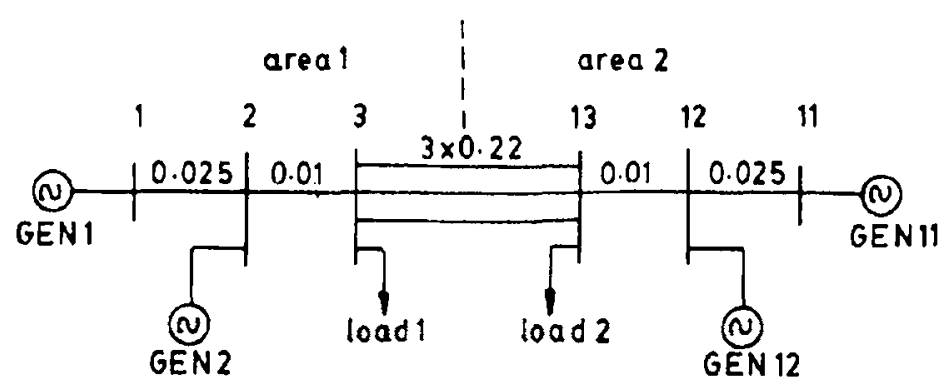

Figure 4. Two-area system. 
Table 1. Two tie-line spectral radius results.

\begin{tabular}{|c|c|c|c|c|c|c|c|c|}
\hline \multirow{2}{*}{$\begin{array}{l}\text { Load } \\
\text { setting } \\
\text { (A) }\end{array}$} & \multirow{2}{*}{$\begin{array}{l}\text { Load } 1 \\
\text { range } \\
(M W)\end{array}$} & \multirow{2}{*}{$\begin{array}{l}\text { Load } 2 \\
\text { range } \\
\text { (MW) }\end{array}$} & \multicolumn{2}{|c|}{$\begin{array}{l}\text { Nominal load } \\
(\mathrm{MW})\end{array}$} & \multicolumn{4}{|c|}{ Spectral radius } \\
\hline & & & Load 1 & Load 2 & Case 1 & Case 2 & Càse 3 & Case 4 \\
\hline $\begin{array}{l}1 \\
2 \\
3 \\
4 \\
5\end{array}$ & $\frac{1127-1147}{}$ & $\begin{array}{l}1767-1807 \\
1807-1847 \\
1847-1887 \\
1887-1927 \\
1927-1967\end{array}$ & $\stackrel{1137}{i}$ & $\begin{array}{l}1787 \\
1827 \\
1867 \\
1907 \\
1947\end{array}$ & $\begin{array}{l}0.5591 \\
0.5492 \\
0.5252 \\
0.6142 \\
0.5095\end{array}$ & $\begin{array}{l}0.7878 \\
0.7921 \\
0.7582 \\
0.9004 \\
0.7427\end{array}$ & $\begin{array}{l}0.6969 \\
0.6768 \\
0.6516 \\
0.7583 \\
0.6322\end{array}$ & $\begin{array}{l}0.6200 \\
0.6111 \\
0.5870 \\
0.6917 \\
0.5775\end{array}$ \\
\hline $\begin{array}{r}6 \\
7 \\
8 \\
9 \\
10\end{array}$ & $\mid$ & $\begin{array}{l}1767-1807 \\
1807-1847 \\
1847-1887 \\
1887-1927 \\
1927-1967\end{array}$ & $\begin{array}{c}1157 \\
1\end{array}$ & $\begin{array}{l}1787 \\
1827 \\
1867 \\
1907 \\
1947\end{array}$ & $\begin{array}{l}0.5977 \\
0.5511 \\
0.5373 \\
0.6156 \\
0.5648\end{array}$ & $\begin{array}{l}0.8540 \\
0.7962 \\
0.7741 \\
0.9029 \\
0.8203\end{array}$ & $\begin{array}{l}0.7394 \\
0.6785 \\
0.6619 \\
0.7588 \\
0.7032\end{array}$ & $\begin{array}{l}0.6660 \\
0.6162 \\
0.6037 \\
0.6969 \\
0.6432\end{array}$ \\
\hline $\begin{array}{l}11 \\
12 \\
13 \\
14 \\
15\end{array}$ & $\left.\right|_{\mid} ^{1167-1187}$ & $\begin{array}{l}1767-1807 \\
1807-1847 \\
1847-1887 \\
1887-1927 \\
1927-1967\end{array}$ & ${ }_{i}^{1177}$ & $\begin{array}{l}1787 \\
1827 \\
1867 \\
1907 \\
1947\end{array}$ & $\begin{array}{l}0.5833 \\
0.5642 \\
0.5568 \\
0.5594 \\
0.5903\end{array}$ & $\begin{array}{l}0.8223 \\
0.8128 \\
0.8084 \\
0.8161 \\
0-8632\end{array}$ & $\begin{array}{l}0.7233 \\
0.6933 \\
0.6855 \\
0.6880 \\
0.7300\end{array}$ & $\begin{array}{l}0.6531 \\
0.6347 \\
0.6288 \\
0.6358 \\
0.6740\end{array}$ \\
\hline $\begin{array}{l}16 \\
17 \\
18 \\
19 \\
20\end{array}$ & $\mid$ & $\begin{array}{l}1767-1807 \\
1807-1847 \\
1847-1887 \\
1887-1927 \\
1927-1967\end{array}$ & $\begin{array}{c}1197 \\
1 \\
1\end{array}$ & $\begin{array}{l}1787 \\
1827 \\
1867 \\
1907 \\
1947\end{array}$ & $\begin{array}{l}0.5749 \\
0.5437 \\
0.5406 \\
0.5422 \\
0.5493\end{array}$ & $\begin{array}{l}0.8059 \\
0.7735 \\
0.7837 \\
0.7924 \\
0.8044\end{array}$ & $\begin{array}{l}0.7130 \\
0.6705 \\
0.6669 \\
0.6692 \\
0.6740\end{array}$ & $\begin{array}{l}0.6469 \\
0.6150 \\
0.6143 \\
0.6211 \\
0.6298\end{array}$ \\
\hline $\begin{array}{l}21 \\
22 \\
23 \\
24 \\
25\end{array}$ & $\left.\right|_{\mid} ^{1207-1227}$ & $\begin{array}{l}1767-1807 \\
1807-1847 \\
1847-1887 \\
1887-1927 \\
1927-1967\end{array}$ & $\left.\right|_{1} ^{1217}$ & $\begin{array}{l}1787 \\
1827 \\
1867 \\
1907 \\
1947\end{array}$ & $\begin{array}{l}0.5927 \\
0.5459 \\
0.5612 \\
0.5525 \\
0.5623\end{array}$ & $\begin{array}{l}0.8341 \\
0.7845 \\
0.8168 \\
0.8078 \\
0.8297\end{array}$ & $\begin{array}{l}0.7323 \\
0.6687 \\
0.6891 \\
0.6805 \\
0.6897\end{array}$ & $\begin{array}{l}0.6704 \\
0.6210 \\
0.6410 \\
0.6368 \\
0.6513\end{array}$ \\
\hline $\begin{array}{l}26 \\
27 \\
28 \\
29 \\
30\end{array}$ & $\begin{array}{c}1227-1247 \\
!\end{array}$ & $\begin{array}{l}1767-1807 \\
1807-1847 \\
1847-1887 \\
1887-1927 \\
1927-1967\end{array}$ & $\stackrel{1237}{!}$ & $\begin{array}{l}1787 \\
1827 \\
1867 \\
1907 \\
1947\end{array}$ & $\begin{array}{l}0.5918 \\
0.5422 \\
0.5572 \\
0.5232 \\
0.5563\end{array}$ & $\begin{array}{l}0.8290 \\
0.7721 \\
0.8095 \\
0.7575 \\
0.8222\end{array}$ & $\begin{array}{l}0.7300 \\
0.6660 \\
0.6854 \\
0.6478 \\
0.6790\end{array}$ & $\begin{array}{l}0.6742 \\
0.6209 \\
0.6429 \\
0.6074 \\
0.6472\end{array}$ \\
\hline $\begin{array}{l}31 \\
32 \\
33 \\
34 \\
35\end{array}$ & $\begin{array}{c}1247-1267 \\
\mid\end{array}$ & $\begin{array}{l}1767-1807 \\
1807-1847 \\
1847-1887 \\
1887-1927 \\
1927-1967\end{array}$ & $\begin{array}{c}1257 \\
\mid \\
\mid\end{array}$ & $\begin{array}{l}1787 \\
1827 \\
1867 \\
1907 \\
1947\end{array}$ & $\begin{array}{l}0.6300 \\
0.5589 \\
0.5672 \\
0.5422 \\
0.5457\end{array}$ & $\begin{array}{l}0.8978 \\
0.8015 \\
0.8252 \\
0.7885 \\
0.8041\end{array}$ & $\begin{array}{l}0.7713 \\
0.6844 \\
0.6958 \\
0.6688 \\
0.6714\end{array}$ & $\begin{array}{l}0.7220 \\
0.6440 \\
0.6585 \\
0.6343 \\
0.6422\end{array}$ \\
\hline $\begin{array}{l}36 \\
37 \\
38 \\
39 \\
40\end{array}$ & $\mid$ & $\begin{array}{l}1767-1807 \\
1807-1847 \\
1847-1887 \\
1887-1927 \\
1927-1967\end{array}$ & $\stackrel{1277}{1}$ & $\begin{array}{l}1787 \\
1827 \\
1867 \\
1907 \\
1947\end{array}$ & $\begin{array}{l}0.6574 \\
0.5989 \\
0.5690 \\
0.5333 \\
0.5649\end{array}$ & $\begin{array}{l}0.9407 \\
0.8678 \\
0.8302 \\
0.7761 \\
0.8390\end{array}$ & $\begin{array}{l}0.7992 \\
0.7272 \\
0.6970 \\
0.6577 \\
0.6879\end{array}$ & $\begin{array}{l}0.7580 \\
0.6947 \\
0.6662 \\
0.6285 \\
0.6680\end{array}$ \\
\hline $\begin{array}{l}41 \\
42 \\
43 \\
44 \\
45\end{array}$ & $\mid$ & $\begin{array}{l}1767-1807 \\
1807-1847 \\
1847-1887 \\
1887-1927 \\
1927-1967\end{array}$ & $\begin{array}{c}1297 \\
1 \\
1\end{array}$ & $\begin{array}{l}1787 \\
1827 \\
1867 \\
1907 \\
1947\end{array}$ & $\begin{array}{l}0.5726 \\
0.6261 \\
0.6011 \\
0.5515 \\
0.5547\end{array}$ & $\begin{array}{l}0.8177 \\
0.9138 \\
0.8823 \\
0.8082 \\
0.8222\end{array}$ & $\begin{array}{l}0.6976 \\
0.7563 \\
0.7310 \\
0.6772 \\
0.6807\end{array}$ & $\begin{array}{l}0.6642 \\
0.7324 \\
0.7083 \\
0.6557 \\
0.6643\end{array}$ \\
\hline $\begin{array}{l}46 \\
47 \\
48 \\
49 \\
50\end{array}$ & ! & $\begin{array}{l}1767-1807 \\
1807-1847 \\
1847-1887 \\
1887-1927 \\
1927-1967\end{array}$ & $\begin{array}{c}1317 \\
\mid\end{array}$ & $\begin{array}{l}1787 \\
1827 \\
1867 \\
1907 \\
1947\end{array}$ & $\begin{array}{l}0.6117 \\
0.5668 \\
0.6060 \\
0.5885 \\
0.5657\end{array}$ & $\begin{array}{l}0.8704 \\
0.8175 \\
0.8920 \\
0.8709 \\
0.8477\end{array}$ & $\begin{array}{l}0.7452 \\
0.6899 \\
0.7352 \\
0.7157 \\
0.6914\end{array}$ & $\begin{array}{l}0.7160 \\
0.6679 \\
0.7212 \\
0.7031 \\
0.6855\end{array}$ \\
\hline
\end{tabular}


terms was done up to $100 \mathrm{~s}$. Beyond this value, the contribution of the integrand was negligible.

Table 1 shows the spectral radius results for the two tie-line cases. In order to cover the $200 \mathrm{MW}$ load variation range, we consider grids of $20 \mathrm{MW}$ variation and perform the analysis over the entire range. For each case the nominal condition is specified and range of variation on load 1 and load 2 is given. Note that we consider the entire range of load. 2 for each range of load 1 in order to cover all possible loading conditions. The results of table 1 clearly show that the system is robustly stable for all the cases as the spectral radii in all cases are $<1$. Furthermore, case 1 is most robust and case 2 is the least robust. Case 3 and case 4 have spectral radii which have the same order of magnitude. These robustness results are now compared with those obtained by time simulation. To test the robustness, the nonlinear system was simulated at the extreme condition for each load setting. The initial conditions are calculated at the extreme condition by running a power flow. A three-phase fault was then placed on bus \#3 and clcared in $5 \mathrm{~ms}$. This is a small disturbance which results in the system moving away from equilibrium, enabling us to study its small signal stability. The stability is analysed in terms of the behaviour of the electrical power output of GEN12. A sample set of plots for the extreme conditions of load setting \#50 where load 1 is $1327 \mathrm{MW}$ and load 2 is $1967 \mathrm{MW}$ is shown in figure 5 where the different cases are compared. We note that all the cases are stable as predicted by the spectral radius test. In addition figure 5a shows that case 1 which corresponds to the small spectral radius settles faster than case 4 which has the larger spectral radius. The relationship between the settling and the relative value of the spectral radius has been observed in other cases as well.

Table 2 shows the spectral radius results for the one tie-line case. The results

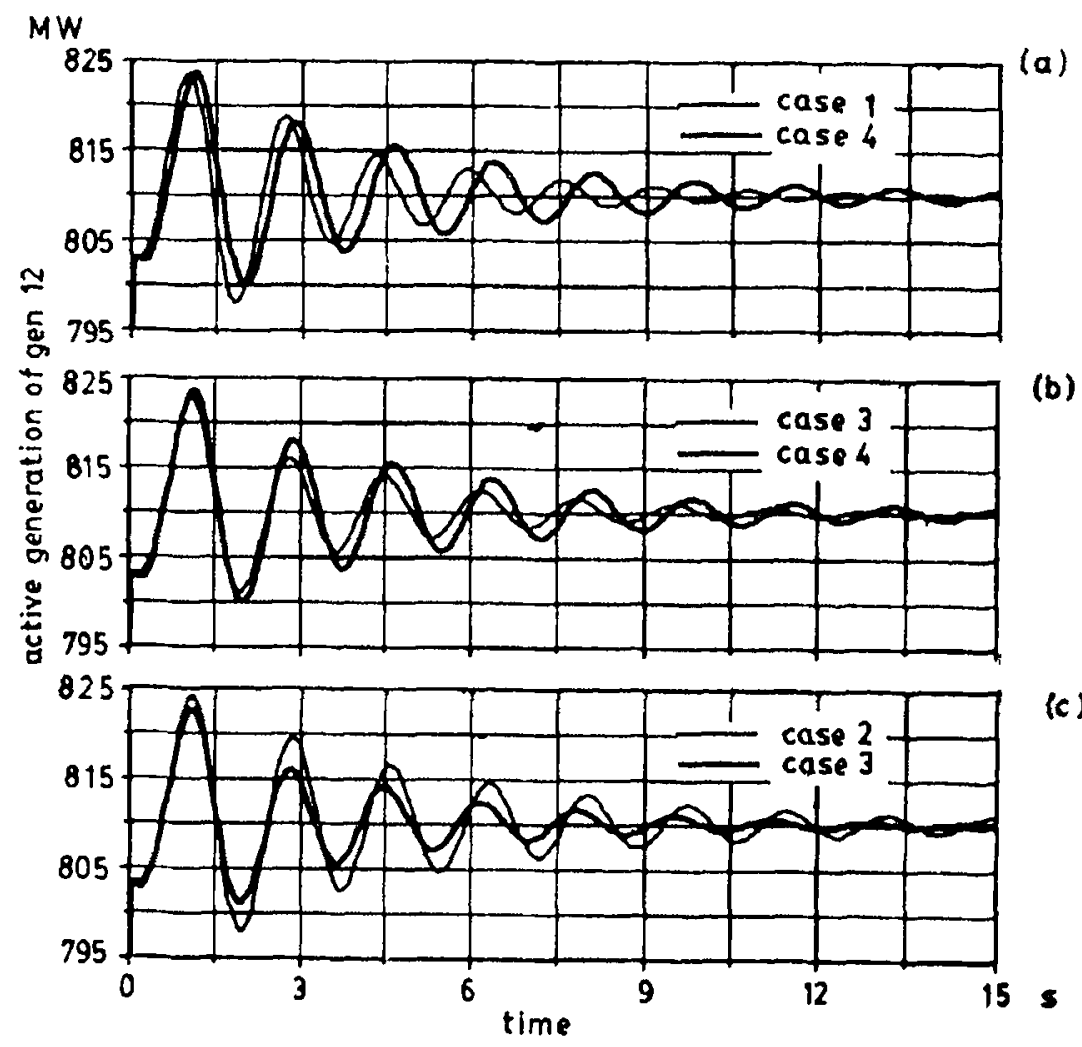

Figure 5. Two tie-line case, load setting \# 50. Analysis from time simulation. 
Table 2. One tie-line spectral radius results.

\begin{tabular}{|c|c|c|c|c|c|c|c|c|}
\hline \multirow{2}{*}{$\begin{array}{l}\text { Load } \\
\text { setting } \\
\text { (\#) }\end{array}$} & \multirow{2}{*}{$\begin{array}{l}\text { Load } 1 \\
\text { range } \\
\text { (MW) }\end{array}$} & \multirow{2}{*}{$\begin{array}{l}\text { Load } 2 \\
\text { range } \\
\text { (MW) }\end{array}$} & \multicolumn{2}{|c|}{$\begin{array}{l}\text { Nominal load } \\
(\mathrm{MW})\end{array}$} & \multicolumn{4}{|c|}{ Spectral radius } \\
\hline & & & Load 1 & Load 2 & Case 1 & Case 2 & Case 3 & Case 4 \\
\hline 1 & $1247-1257$ & $1927-1937$ & 1252 & 1932 & 0.3901 & 4.0293 & 0.9699 & 0.7020 \\
\hline 2 & $1247-1257$ & $1937-1947$ & 1252 & 1942 & 0.3852 & $3 \cdot 7445$ & 0.9562 & 0.6799 \\
\hline 3 & $1247-1257$ & $1947-1957$ & 1252 & 1952 & 0.3405 & $3 \cdot 1568$ & 0.8224 & 0.5969 \\
\hline 4 & $1247-1257$ & $1957-1967$ & 1252 & 1962 & 0.3077 & 2.7905 & 0.7316 & 0.5397 \\
\hline 5 & $1257-1267$ & $1927-1937$ & 1262 & 1932 & 0.3198 & 3.8226 & 0.8017 & 0.6032 \\
\hline 6 & $1257-1267$ & $1937-1947$ & 1262 & 1942 & 0.3717 & $4 \cdot 3228$ & 0.9583 & 0.6915 \\
\hline 7 & $1257-1267$ & $1947-1957$ & 1262 & 1952 & 0.3706 & $4 \cdot 1560$ & 0.9495 & 0.6834 \\
\hline 8 & $1257-1267$ & $1957-1967$ & 1262 & 1962 & 0.3002 & $3 \cdot 1676$ & 0.7400 & 0.5408 \\
\hline
\end{tabular}

indicate that case 1 is the most robust, followed by case 4 and case 3 . In addition, case 2 is found to be unstable. The nonlinear time simulation was repeated for setting \#8 load $11267 \mathrm{MW}$ and load $21967 \mathrm{MW}$. These results are shown in figure 6. We again note that figure $6 \mathrm{a}$ confirms that case 1 is the most robust of all cases. Figure $6 \mathrm{~b}$ shows that case 4 is more robust than case 3 as it settles down to a lower value at about 12 less than case 3 even though it has a higher initial peak. The spectral radius predicts this as shown in table 2 where the spectral radius for case 4 is 0.5408 and case 3 is 0.7400 . Finally, figure $6 \mathrm{c}$ clearly indicates that case 2 is unstable as predicted by the spectral radius of $3 \cdot 1676$. The spectral radius for this case remained well above 1 no matter how small a load range was chosen.

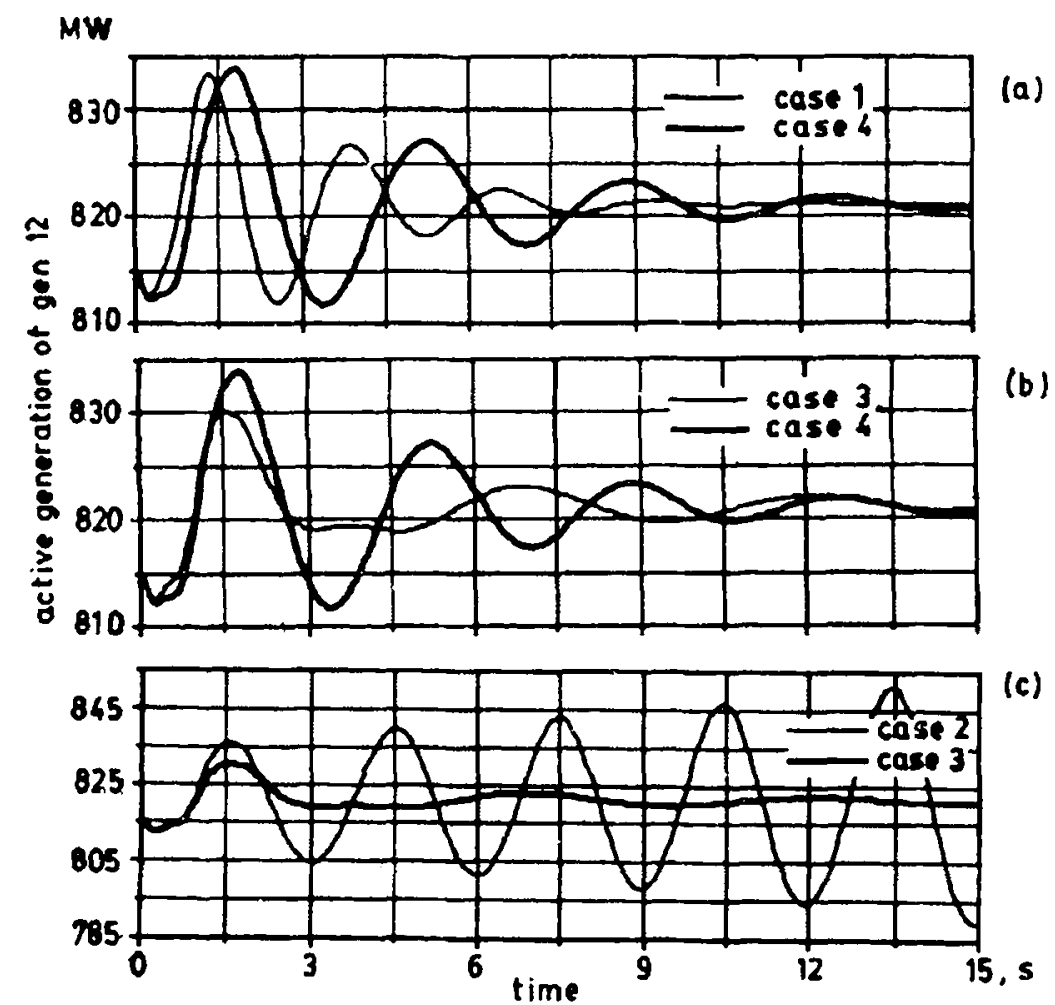

Figure 6. One tie-line case, load setting \#8. Results from time simulation. 


\section{Conclusions}

A novel technique is developed in this paper to analyse the robust stability of control settings (gains and time constants). The basic principles governing the technique are presented and adapted to power systems.

The control features considered include exciters, power system stabilizers, and governors. The stability robustness of these controls is then analysed for a range of loading conditions.

Preliminary results of the procedure applied to a sample test system clearly indicate the efficacy of the procedure in predicting stability robustness. The forrnulation of the procedure can be extended to include any modelling feature. The procedure can also be used to aid in robust design by applying it repetitively.

\section{References}

Anderson P M, Fouad A A 1977 Power system stability and control (Ames, IA: Iowa State University Press)

Berman A, Blemmons R 1979 Nonnegative matrices in the mathematical sciences (New York: Academic Press)

Cressap R L, Hauer J F 1981 Emergence of a new swing mode in the western power system. IEEE Trans. Power Appar. Syst. PAS-100: 2037-2043

Dahleh M A, Ohta Y 1988 A necessary and sufficient condition for robust BIBO stability. Syst. Control Lett. 11: 271-275

Doyle J C 1982 Analysis of feedback systems with structured uncertainty. Proc. Inst. Elec. Eng. D129: 242-250

Kharnmash M 1993 Necessary and sufficient conditions for the robustness of time-varying systems with applications to sampled-data systems. IEEE Trans. Autom. Control 38:49-57

Khammash M, Pearson J B 1991 Performance robustness of discrete-time systems with structured uncertainty. IEEE Trans. Autom. Control AC-36: 398-412

Khammash M, Pearson J B 1993 Analysis and design for robust performance with structured uncertainty. Syst. Control Lett: 20: 179-187

Kharitonov V L 1978a Asymptotic stability of an equilibrium position of a family of systems of linear differential equations. Differntial'nye Uraveniya 14: 1483-1485

Kharitonov V L $1978 \mathrm{~b}$ On a generalization of a stability criterion. Akademii mauk Kahskoi SSR, fiziko-matematicheskaia 1: 53-57

Klein M, Rogers G J, Kundur P 1991 A fundamental study of interarea oscillations in power systems. IEEE Winter Power Meeting Paper no. 91wM015-8-PWRS

Kundur P, Klein M, Rogers G J, Zwyno M 1989a Application of power system stabilizers for enhancement of overall systems stability. IEEE Trans. Power Syst. PAS-4: 614-622

Kundur P, Rogers G J, Wong D Y 1988 The small signal stability program package 1, EPRI Final Report, EL-5798

Kundur P, Roger G J, Wong D Y 1989 b Extended transient-midterm stability program package: Version 2.0, Users manuals. EPRI EL-6648

Martins N, Lima L T G 1990 Eigenvalue and frequency domain analysis of small-signal electromechanical stability problems. Special Publication: IEEE Power Enyineering Society, 90TH0292-3-PWR: 17-33

Roger G J, Kundur P 1990 Small signal stability of power systems. Special Publication: IEEE Power Engineering Society, 90TH0292-3-PWR: 5-16

Safonov M G 1982 Stability margins of diagonally perturbed multivariable feedback systems. Proc. Inst. Elec. Eng. 129: 251-256 